\title{
Pseudopotential Calculations for Methyl Compounds of Zine and Magnesium
}

\author{
M. Kaupp, H. Stoll, and H. Preuss* \\ Institut für Theoretische Chemie, Universität Stuttgart, Pfaffenwaldring 55, D7000 Stuttgart 80, West Germany
}

Received 29 January 1990; accepted 2 May 1990

\begin{abstract}
Pseudopotentials and valence basis sets to be used in calculations for organometallic compounds of zinc and magnesium have been tested in calculations for the $M\left(\mathrm{CH}_{3}\right)_{n}(M=\mathrm{Zn}, \mathrm{Mg} ; n=1,2)$ molecules. Valence correlation effects are treated at the SDCI and CEPA levels. The capability of a polarization potential on zinc to account for the valence shell contracting effect of core valence correlation is studied. Properties considered are geometries, force constants, Mulliken populations, ionization potentials, atomization, and binding energies. Differences in bonding between the two dimethyl compounds are discussed.
\end{abstract}

\section{INTRODUCTION}

Considering the fact that organozinc and organomagnesium compounds belong to the most important organometallic compounds in synthesis and that zinc and magnesium are of crucial importance also in many biological systems, it is surprising that reliable $a b$ initio data on these compounds are very scarce.

Comparing the chemistry of zinc and magnesium is a very rewarding field, because in spite of striking similarities (e.g., atomic and ionic radii, aqueous chemistry) the presence of a filled $3 d$-shell in the zinc atom leads to significant differences (e.g., lower reactivity of the $\mathrm{Zn}$ organometallic compounds). The difference of the simple dialkyl compounds is particularly apparent. Dimethyl and diethylzinc, which were already discovered in 1848 by Frankland (cf. reference 1), are volatile liquids that consist of monomers with $\mathrm{CZnC}$-angles of $180^{\circ 2}$ whereas their magnesium analogues are polymeric solids with bent $\mathrm{CMgC}$ units $^{3}$ (comparable to the dialkylberyllium compounds) that did not receive much attention in the shadow of the famous Grignard reagents.

For our intended calculations on relatively large complexes of dialkylzinc and dialkylmagnesium compounds with unsaturated nitrogen ligands ${ }^{4}$ we had to choose a practicable $a b$ initio approach. The use of pseudopotentials on the metals and for the larger systems even on the first-row elements offers obvious benefits. The question remaining was how large the cores on the metals can be chosen and to what extent the valence basis sets can be truncated without introducing significant errors. Furthermore, be-

*To whom all correspondence should be addressed. cause correlation effects can hardly be treated accurately in larger systems, one should at least be able to estimate, from calculations on smaller molecules, errors which are to be expected at the Hartree-Fock level of theory.

Therefore we have chosen the dimethyl compounds and the methyl radicals of zinc and magnesium to compare results of pseudopotential calculations with different cores (for $M=\mathrm{Zn}$ ) or pseudopotential and all-electron results (for $M=\mathrm{Mg}$ ) as well as different basis sets and methods to account for correlation effects; this comparison is made for various properties like geometries, force constants, Mulliken populations, and the energies of ionization, atomization and binding.

While model potential ${ }^{5 a}$ and all-electron calculations for $\mathrm{Zn}\left(\mathrm{CH}_{3}\right)_{2}$ (in a paper by Barandiaran et al. on basis sets for studies of transition metal compounds ${ }^{5 b}$ and in a comparison of calculated and experimental geometries by Almenningen et al. ${ }^{2}$ ) and for $\mathrm{MgCH}_{3}$ and $\mathrm{HMgCH}_{3}{ }^{6}$ have been done before, the only available comparison of the two dimethyl compounds are single point pseudopotential calculations by Ratner et al. ${ }^{7}$

\section{METHODS}

\section{Pseudopotentials}

The pseudopotentials $V(r)$ employed are semilocal potentials of the form

$$
\begin{gathered}
V(r)=-\frac{Q}{r}+\sum_{l=0}^{l_{\max }} \sum_{i=1}^{n} C_{l i} \exp \left(-c_{l i} r^{2}\right) \cdot \mathbf{P}_{l} \\
\mathbf{P}_{l}=\sum_{m l=-l}^{l}\left|Y_{l, m}\right\rangle\left\langle Y_{l, m l}\right|
\end{gathered}
$$

where $Q$ is the core charge and $P_{l}$ is the projector 
on angular momentum $l$. For zinc the two pseudopotentials compared are a pseudopotential with a Ne-like core ${ }^{8}$ adjusted in an atomic multielectron fit $(\mathrm{MEFIT})^{9}$ to relativistic Dirac-Fock energies and a pseudopotential with an $\operatorname{Ar}\left[3 d^{10}\right]$-core ${ }^{10}$ fitted with MEFIT to quasirelativistic energies (the parameters of this pseudopotential are listed in the appendix).

For the simulation of core valence correlation effects in conjunction with the latter pseudopotential a semiempirical polarization potential $V_{\mathrm{Pol}}$ of the form

$$
\begin{gathered}
V_{\mathrm{Pol}}=-\frac{1}{2} \alpha_{D}\left(\mathbf{f}\left(g^{-1} \mathbf{r}\right)\right)^{2} \\
g(r)=\left(1-\exp \left(-\delta r^{2}\right)\right)^{1 / 2}
\end{gathered}
$$

is used, where $\mathbf{f}$ is the field generated by valence electrons and surrounding cores at the site of a given core, $\alpha_{D}$ is the core dipole polarizability and $\delta$ is a cutoff parameter. ${ }^{11}$

Single-electron-fit (SEFIT) pseudopotentials adjusted to experimental and Dirac-Fock data with a Ne-like core for magnesium and with a He-like core for carbon, are taken from references 12 and 13 , respectively. In some cases for these two elements all electrons are treated explicitly.

\section{Basis Sets}

Generally Gaussian type orbitals (GTO) are employed. For the Ne-core pseudopotential on zinc the optimized $(8 s 7 p 6 d) /[6 s 5 p 3 d]$ basis set published with the potential ${ }^{8}$ is used. For some calculations including valence correlation one set of $f$ functions ( $\alpha=0.28$ ) has been added to enable angular correlation of the $d$ orbitals.

For all-electron calculations on the magnesium compounds the $(12 s 9 p) /[6 s 4 p]$ basis set of McLean and Chandler ${ }^{14}$ has been employed which for some correlation calculations is augmented by one set of $d$-functions ( $\alpha=0.11$ ).

For the two-valence-electron pseudopotentials on the metals $(4 s 2 p) /[3 s 2 p]$ and $(3 s 1 p) /[2 s 1 p]$ basis sets have been optimized (see appendix).

For carbon in the all-electron case the $(9 s 5 p 1 d) /$ $[3 s 2 p 1 d]$ basis set of Dunning and $\mathrm{Hay}^{15}$ is used. The $(4 s 1 p) /[3 s 1 p]$ and $(4 s) /[3 s]$ basis sets for hydrogen are taken from the same article.

Two basis sets $(4 s 4 p) /[2 s 2 p]$ and $(3 s 3 p) /[2 s 2 p]$ optimized for the pseudopotential on carbon and a $(3 s) /[2 s]$ basis set for hydrogen have also been generated (see appendix).

The combinations of these basis sets as shown in Table I reveal the following pattern: The combinations $\mathrm{B} 1$ with Ne-like core and a relatively large basis set on zinc and relatively large allelectron basis sets on magnesium and carbon serve as reference calculations (B1+ denotes calculations with additional $f$ and $d$ functions on $\mathrm{Zn}$ and $\mathrm{Mg}$, respectively). The sets $\mathrm{B} 2$ introduce the two-valence electron pseudopotentials with still relatively flexible basis sets on the metals.

The pseudopotential on carbon with a $(4 s 4 p 1 d)$ / [2s $2 p 1 d]$ basis set (the exponent of the $d$ function is taken from reference 15) is introduced in combination B3. The polarization functions on carbon and hydrogen are removed in B4, while B5 reduces the basis sets on the metals to $(3 s 1 p) /$ [ $2 s 1 p]$ as well as the number of primitive functions on carbon and hydrogen.

\section{Methods to Account for Electron Correlation}

Valence correlation is included in our calculations by a singles + doubles CI with Davidson's correction ${ }^{17}$ added (SDCI $+Q$ ), or using the coupledelectron pair approximation ${ }^{18}$ (CEPA 1). The programs employed for these calculations are MELD $^{19}$ and MOLPRO, ${ }^{18,20}$ respectively. The results of SDCI + Q- and CEPA 1-calculations have been found to be very similar for the $M \mathrm{Me}_{2}$ $(M=\mathrm{Zn}, \mathrm{Mg})$ molecules, so both schemes are used throughout this article.

The magnitude of the correlation energy calculated strongly changes, of course, with the size of the pseudopotential core employed or when explicitly excluding core orbitals from correlation.

Table II shows that for zinc there is a significant contribution from the $d$ shell to the correlation energy, almost half of it originating from angular correlation.

\section{RESULTS AND DISCUSSION}

\section{Dimethyl Compounds}

\section{Geometries}

The barrier of rotation around the $M C$ bonds was found to be negligible in our calculations for both $M=\mathrm{Zn}$ and $M=\mathrm{Mg}$ (which is consistent with the experimental data on dimethylzinc ${ }^{21}$ ). In subsequent calculations, we chose an eclipsed conformation for geometries close to the energy minimum. Both molecules were generally found to have $\mathrm{CMC}$-angles of $180^{\circ}$ in their ground state. The optimized geometries are summarized in Tables III and IV.

At the Hartree-Fock level all pseudopotential/ basis set combinations (B1 through B5) used for dimethylzinc give geometries in good agreement with the all-electron SCF calculations of Almenningen et al. $^{2}$ but they overestimate the experimental $\mathrm{ZnC}$-distance by ca. $5 \mathrm{pm}$. This is consistent with results of Barandiaran et al. ${ }^{5 b}$ which show that while minimal basis sets or basis sets with a small inner-core part under- 
Table I. Different basis set combinations employed.

\begin{tabular}{|c|c|c|c|c|c|}
\hline & B1 & B2 & B3 & B4 & B5 \\
\hline $\begin{array}{l}\text { Zn } \\
\text { Core size } \\
\text { Fit }^{\mathrm{c}} \\
\text { Primitives } \\
\text { Contr. scheme }\end{array}$ & $\begin{array}{l}\mathrm{Ne}^{\mathrm{a}} \\
\mathrm{MDF}^{\mathrm{c}} \\
8 s 7 p 6 d^{\mathrm{a}} \\
{[511111 / 22111 / 411]}\end{array}$ & $\begin{array}{l}\operatorname{Ar}\left[3 d^{10}\right]^{b} \\
\operatorname{MWB}^{c} \\
4 s 2 p^{d} \\
{[211 / 11]}\end{array}$ & $\begin{array}{l}\operatorname{Ar}\left[3 d^{10}\right]^{b} \\
\operatorname{MWB}^{\mathrm{b}} \\
4 s 2 p^{d} \\
{[211 / 11]}\end{array}$ & $\begin{array}{l}\operatorname{Ar}\left[3 d^{10}\right]^{b} \\
\operatorname{MWB} B^{c} \\
4 s 2 p^{d} \\
{[211 / 11]}\end{array}$ & $\begin{array}{l}\operatorname{Ar}\left[3 d^{10}\right]^{\mathrm{b}} \\
\mathrm{MWB}^{\mathrm{c}} \\
3 s 1 p^{\mathrm{d}} \\
{[21 / 1]}\end{array}$ \\
\hline $\begin{array}{l}\mathrm{Mg} \\
\text { Core size } \\
\text { Fit }^{\mathrm{c}} \\
\text { Primitives } \\
\text { Contr. scheme }\end{array}$ & \begin{tabular}{l}
\multicolumn{1}{c}{$\frac{-}{12 s 9 p^{f}}$} \\
{$[631111 / 6111]$}
\end{tabular} & $\begin{array}{l}\mathrm{Ne}^{\mathrm{e}} \\
\mathrm{SDF}^{\mathrm{e}} \\
4 s 2 p^{\mathrm{d}} \\
{[211 / 11]}\end{array}$ & $\begin{array}{l}\mathrm{Ne}^{\mathrm{e}} \\
\mathrm{SDF}^{\mathrm{c}} \\
4 s 2 p^{\mathrm{d}} \\
{[211 / 11]}\end{array}$ & $\begin{array}{l}\mathrm{Ne}^{e} \\
\mathrm{SDF}^{c} \\
4 s 2 p^{d} \\
{[211 / 11]}\end{array}$ & $\begin{array}{l}\mathrm{Ne}^{\mathrm{e}} \\
\mathrm{SDF}^{\mathrm{c}} \\
3 s 1 p^{\mathrm{d}} \\
{[21 / 1]}\end{array}$ \\
\hline $\begin{array}{l}\text { C } \\
\text { Core size } \\
\text { Fit }^{\mathrm{c}} \\
\text { Primitives } \\
\text { Contr. scheme }\end{array}$ & $\begin{array}{l}- \\
9 s 5 p 1 d^{\mathrm{g}} \\
{[721 / 41 / 1]}\end{array}$ & $\begin{array}{l}\overline{-} \\
9 s 5 p 1 d^{\mathrm{g}} \\
{[721 / 41 / 1]}\end{array}$ & $\begin{array}{l}\mathrm{He}^{\mathrm{h}} \\
\mathrm{SDF}^{\mathrm{c}} \\
4 s 4 p 1 d^{\mathrm{d}} \\
{[31 / 31 / 1]}\end{array}$ & $\begin{array}{l}\mathrm{He}^{\mathrm{h}} \\
\mathrm{SDF}^{\mathrm{c}} \\
4 s 4 p^{\mathrm{d}} \\
{[31 / 31]}\end{array}$ & $\begin{array}{l}\mathrm{He}^{\mathrm{h}} \\
\mathrm{SDF}^{\mathrm{c}} \\
3 s 3 p^{\mathrm{d}} \\
(21 / 21 \mathrm{~J}\end{array}$ \\
\hline $\begin{array}{l}\mathrm{H} \\
\text { Primitives } \\
\text { Contr. scheme }\end{array}$ & $\begin{array}{l}4 s 1 p^{\mathrm{B}} \\
{[31 / 1]}\end{array}$ & $\begin{array}{l}4 s 1 p^{\mathrm{g}} \\
{[31 / 1]}\end{array}$ & $\begin{array}{l}4 s 1 p^{g} \\
{[31 / 1]}\end{array}$ & $\begin{array}{l}4 s^{B} \\
{[31]}\end{array}$ & $\begin{array}{l}3 s^{d} \\
{[21]}\end{array}$ \\
\hline
\end{tabular}

${ }^{\mathrm{a}}$ M. Dolg et al. ${ }^{\mathrm{B}}$. ${ }^{\mathrm{b}} \mathrm{M}$. Dolg ${ }^{10}$ (see appendix). 'Shorthand notations for the fitting procedures: MWB = MEFIT to quasirelativistic Wood-Boring ${ }^{16}$ energies, MDF, SDF $=$ MEFIT or SEFIT, respectively, to Dirac-Fock energies. ${ }^{d}$ See appendix. ${ }^{\mathrm{P}}$. Fuentealba et al. ${ }^{12}{ }^{\mathrm{f}} \mathrm{A}$. D. McLean et al. ${ }^{14}$. ${ }^{8}$ T. H. Dunning et al. ${ }^{15}$. ${ }^{\mathrm{h}} \mathrm{G}$. Igel-Mann et al. ${ }^{13}$.

Table II. Correlation energies of the dimethyl compounds.

\begin{tabular}{|c|c|c|c|c|c|}
\hline \multirow{2}{*}{$\begin{array}{l}\text { Dimethylzinc } \\
\text { Method }\end{array}$} & \multirow[b]{2}{*}{ Excl. Orb. ${ }^{\mathrm{a}}$} & \multicolumn{4}{|c|}{ Dimethylmagnesium } \\
\hline & & $E_{\text {Corr }}$ [a.u.] & Method & Excl. orb. ${ }^{a}$ & $E_{\text {Corr }}$ [a.u.] \\
\hline $\begin{array}{l}\mathrm{B} 1+/ \mathrm{CEPA} 1 \\
\mathrm{~B} 1+/ \mathrm{SDCI}+\mathrm{Q} \\
\mathrm{B} 1 / \mathrm{CEPA} 1 \\
\mathrm{~B} 1 / \mathrm{CEPA} 1 \\
\mathrm{~B} 2 / \mathrm{CEPA} 1 \\
\mathrm{~B} 3 / \mathrm{V}_{\mathrm{Pol}} / \mathrm{SDCI}+\mathrm{Q} \\
\mathrm{B} 3 / \mathrm{CEPA} 1\end{array}$ & $\begin{array}{l}\mathrm{Zn} 3 s, 3 p ; \mathrm{C} 1 s \\
\mathrm{Zn} 3 s, 3 p ; \mathrm{C} 1 s \\
\mathrm{Zn} 3 s, 3 p ; \mathrm{C} 1 s \\
\mathrm{Zn} 3 s, 3 p, 3 d ; \mathrm{C} 1 s \\
\mathrm{C} 1 s\end{array}$ & $\begin{array}{l}-0.65260 \\
-0.66700 \\
-0.53984 \\
-0.36017 \\
-0.36381 \\
-0.35969^{b} \\
-0.36632\end{array}$ & $\begin{array}{l}\mathrm{B} 1+/ \mathrm{CEPA} 1 \\
\mathrm{~B} 1 / \mathrm{CEPA} 1 \\
\mathrm{~B} 1 / \mathrm{CEPA} 1 \\
\mathrm{~B} 2 / \mathrm{CEPA} 1 \\
\mathrm{~B} 3 / \mathrm{CEPA} 1 \\
\mathrm{~B} 3 / \mathrm{SDCI}+\mathrm{Q}\end{array}$ & $\begin{array}{l}\mathrm{Mg} 1 s, \mathrm{C} 1 s \\
\mathrm{Mg} 1 s, \mathrm{C} 1 s \\
\mathrm{Mg} 1 s, 2 s, 2 p, \mathrm{C} 1 s \\
\mathrm{C} 1 s\end{array}$ & $\begin{array}{l}-0.39820 \\
-0.39124 \\
-0.36436 \\
-0.36346 \\
-0.36500 \\
-0.36116\end{array}$ \\
\hline
\end{tabular}

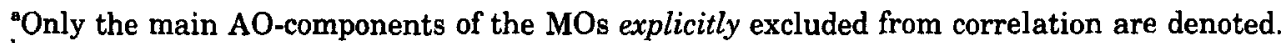

'Only the valence correlation energy is specified.

Table III. Geometries and MC-force constants of dimethylzinc.

\begin{tabular}{|c|c|c|c|c|}
\hline & $R-\mathrm{ZnC}[\mathrm{pm}]$ & $<\mathrm{ZnCH}$ & $R-\mathrm{CH}[\mathrm{pm}]$ & $\mathbf{k}(\mathrm{ZnC})[\text { a.u. }]^{\mathrm{a}}$ \\
\hline Experiment $^{\mathbf{b}}$ & 193.0 & 112.5 & - & 一 \\
\hline Allel. calc. & 197.7 & 111.5 & - & - \\
\hline B1 & 197.7 & 111.4 & 109.5 & 0.286 \\
\hline $\mathrm{B} 2$ & 198.5 & 111.5 & 109.5 & 0.277 \\
\hline B3 & 198.0 & 111.6 & 109.0 & 0.258 \\
\hline B4 & 197.9 & 111.2 & 109.2 & 0.264 \\
\hline B5 & 198.2 & 111.2 & 108.7 & 0.264 \\
\hline $\mathrm{B} 1+/ \mathrm{CEPA} 1$ & 194.0 & 111.4 & 110.5 & 0.291 \\
\hline $\mathrm{B} 1 / \mathrm{CEPA} 1^{\mathrm{c}}$ & $201.1^{\mathrm{d}}$ & - & - & 0.242 \\
\hline $\mathrm{B} 2 / \mathrm{CEPA} 1$ & $199.0^{\mathrm{d}}$ & - & - & 0.240 \\
\hline $\mathrm{B} 3 / \mathrm{V}_{\mathrm{Pol}} / \mathrm{SDCI}+\mathrm{Q}$ & 194.0 & 111.4 & 109.4 & 0.274 \\
\hline B3/CEPA 1 & $198.4^{\mathrm{d}}$ & - & - & 0.235 \\
\hline
\end{tabular}

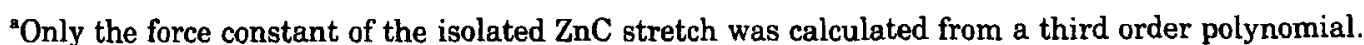

bAlmenningen et al. ${ }^{2}$.

'All MOs with mainly $d$-orbital-character on zinc have been excluded from correlation.

${ }^{d}$ Only the $\mathrm{ZnC}$-distance has been optimized, starting from the corresponding SCF-geometry. 
Table IV. Geometries and MC-force constants of dimethylmagnesium.

\begin{tabular}{lcccc}
\hline & $R-\mathrm{MgC}[\mathrm{pm}]$ & $<\mathrm{MgCH}$ & $R-\mathrm{CH}[\mathrm{pm}]$ & $\mathbf{k}(\mathrm{MgC})[\text { a.u. }]^{\mathrm{a}}$ \\
\hline Experiment & $224^{\mathrm{b}}$ & - & - & - \\
B1 & 211.0 & 112.3 & 109.8 & 0.215 \\
B2 & 210.0 & 112.2 & 109.8 & 0.214 \\
B3 & 210.9 & 112.1 & 109.4 & 0.208 \\
B4 & 209.5 & 111.9 & 109.4 & 0.215 \\
B5 & 209.0 & 111.7 & 108.8 & 0.216 \\
B1+/CEPA 1 & 210.8 & 111.4 & 110.7 & 0.206 \\
B3/SDCI + Q & $210.1^{\mathrm{c}}$ & - & - & 0.196 \\
\hline
\end{tabular}

${ }^{a}$ Only the force constant of the isolated $\mathrm{MgC}$ stretch was calculated from a third-order polynomial.

whe experimental value was taken from the polymeric solid (Wei $\beta$ [3]) where the interatomic distances are probably much longer than for the unknown gas phase structure.

'Only the MgC-distance was optimized, starting from the corresponding SCF-geometry

estimate the $\mathrm{ZnC}$-distance larger basis sets overestimate it.

The deviation from experiment can only be reduced by considering both valence and core valence correlation. Neglect of the latter leads to even larger $\mathrm{ZnC}$-distances than the SCF values and consequently yields too small $\mathrm{ZnC}$ force constants. The polarization potential together with an SDCI $+Q$ calculation to account for valence correlation significantly improves the $\mathrm{ZnC}$ distance and force constant compared to the calculation with valence correlation only.

For dimethylmagnesium the experimental MCdistance taken from the polymeric solid state structure $^{3 \mathrm{a}}$ is not a good criterion. Taking our best calculation (with B1+/CEPA 1) as a reference (there are no calculations or gas phase data available in the literature), the results suggest that the role of correlation for geometry is only minor; the differences between the various basis sets are below $2 \mathrm{pm}$ and $1^{\circ}$ in distances and angles, respectively. The SCF calculations give the usual 10 to $20 \%$ overestimate of the MC force constant.

\section{Ionization Potentials}

In view of the experimental value of $9.46 \mathrm{eV}$ for dimethylzinc, ${ }^{22}$ Koopmans' theorem seems to hold well for this compound whereas the $\triangle \mathrm{SCF}$-values consistently are too small by about 0.8 to $0.9 \mathrm{eV}$ (Table V). With B1+/CEPA 1 the major part of the correlation contribution is recovered whereas B3/CEPA 1 yields a much too small contribution. Obviously core valence correlation plays an important role for the first ionization energy in dimethylzinc. Unfortunately the polarization potential does not reproduce this effect.

For dimethylmagnesium no experimental data are available. Comparison with the CEPA 1 calculations suggests, however, that the $\triangle \mathrm{SCF}$ values are to be preferred here over Koopmans energies.

\section{Energies of Atomization}

The calculated values of atomization energies are listed in Table VI. In addition to the uncorrected values, i.e. values obtained by subtracting from the molecular energies the sum of atomic energies evaluated with the corresponding atomic basis sets, we give values corrected for basis set superposition errors (BSSE) where the atomic energies are evaluated with the molecular basis. ${ }^{23}$

Generally B1 to B3 show comparable accuracy while $\mathrm{B} 4$ shows the effect of the missing polarization functions on carbon and hydrogen. For B5 the BSSE becomes significant, leading to higher uncorrected values than for $B 4$.

Table V. First ionization potentials of the dimethyl compounds [eV].

\begin{tabular}{|c|c|c|c|c|c|}
\hline \multicolumn{3}{|c|}{ Dimethylzinc } & \multicolumn{3}{|c|}{ Dimethylmagnesium } \\
\hline & Koopmans & $\triangle \mathrm{SCF}$ & & Koopmans & $\triangle \mathrm{SCF}$ \\
\hline \multirow[t]{2}{*}{$\begin{array}{l}\text { B1 } \\
\text { B2 } \\
\text { B3 } \\
\text { B4 } \\
\text { B5 }\end{array}$} & $\begin{array}{l}9.71 \\
9.51 \\
9.45 \\
9.49 \\
9.36\end{array}$ & $\begin{array}{l}8.78 \\
8.62 \\
8.56 \\
8.63 \\
8.59\end{array}$ & $\begin{array}{l}\text { B1 } \\
\text { B2 } \\
\text { B3 } \\
\text { B4 } \\
\text { B5 }\end{array}$ & $\begin{array}{l}9.30 \\
9.27 \\
9.20 \\
9.23 \\
9.15\end{array}$ & $\begin{array}{l}8.44 \\
8.57 \\
8.52 \\
8.58 \\
8.54\end{array}$ \\
\hline & & $\triangle \mathrm{CEPA} 1$ & & & $\triangle$ CEPA 1 \\
\hline \multicolumn{2}{|c|}{$\begin{array}{l}\mathrm{B} 1+/ \mathrm{CEPA} 1 \\
\mathrm{~B} 3 / \mathrm{V}_{\mathrm{Pol}} / \mathrm{SDCI}+\mathrm{Q} \\
\mathrm{B} 3 / \mathrm{CEPA} 1\end{array}$} & $\begin{array}{l}9.23 \\
8.77 \\
8.76\end{array}$ & \multicolumn{2}{|c|}{$\begin{array}{l}\mathrm{B} 1+/ \mathrm{CEPA} 1 \\
\mathrm{~B} 1 / \mathrm{CEPA} 1 \\
\mathrm{~B} 3 / \mathrm{CEPA} 1\end{array}$} & $\begin{array}{l}8.45 \\
8.52 \\
8.45\end{array}$ \\
\hline
\end{tabular}


Table VI. Energies of atomization for the dimethyl compounds [a.u.].

\begin{tabular}{|c|c|c|c|c|c|}
\hline \multicolumn{3}{|c|}{ Dimethylzinc } & \multicolumn{3}{|c|}{ Dimethylmagnesium } \\
\hline & Uncorrected $^{\mathrm{a}}$ & Corrected $^{a}$ & & Uncorrected $^{\mathrm{a}}$ & Corrected ${ }^{\mathrm{a}}$ \\
\hline B1 & 0.844873 & 0.843728 & B1 & 0.841705 & 0.840906 \\
\hline $\mathrm{B} 2$ & 0.833401 & 0.832689 & $\mathrm{~B} 2$ & 0.842226 & 0.841350 \\
\hline B3 & 0.838604 & 0.837327 & $\mathbf{B} 3$ & 0.846865 & 0.845415 \\
\hline B4 & 0.803797 & 0.802563 & $\mathrm{~B} 4$ & 0.812660 & 0.811444 \\
\hline B5 & 0.811695 & 0.799141 & B5 & 0.824176 & 0.811368 \\
\hline $\mathrm{B} 1+/ \mathrm{CEPA} 1$ & 1.040717 & 1.020426 & $\mathrm{BI}+/ \mathrm{CEPA} 1$ & 1.034342 & \\
\hline B3/CEPA 1 & 1.022780 & 1.007117 & B1/CEPA 1 & 1.024956 & 1.008632 \\
\hline $\mathrm{B} 3 / \mathrm{V}_{\mathrm{Pal}} / \mathrm{SDCI}+\mathrm{Q}$ & 1.021204 & & $\mathrm{~B} 3 / \mathrm{CEPA} 1$ & 1.028164 & 1.013193 \\
\hline
\end{tabular}

${ }^{2}$ See text.

Barandiaran et al. ${ }^{5 b}$ showed that large basis sets lead to values between 0.8 and 0.85 a.u. whereas minimal basis sets and basis sets with small inner-core parts give values considerably smaller than 0.8 a.u.

Correlation effects amount to about 0.2 a.u. for both species, $\leq 10 \%$ of which is contributed by core valence correlation for dimethylzinc. The experiment gives about 1.06 a.u. for this molecule. ${ }^{\text {sb }}$ Again the polarization potential on zinc can not faithfully simulate the effect of core valence correlation.

\section{Mulliken Charges}

The strong basis set dependency of Mulliken charges can be seen from Table VII. The different nodal structure of the pseudoorbitals for different core definitions also has a significant effect on the Mulliken populations (e.g., see B1, B2 for $M=\mathrm{Zn}$ in Table VII).

Therefore one should only compare Mulliken populations for similar basis sets and a similar valence space.

For the basis set combinations from B2 to B5 this is possible; in each case magnesium has a higher positive charge than zinc, in agreement with chemical experience. A contradictory result of Ratner et al. ${ }^{7}$ can be attributed to an unfortu- nate choice of geometries in conjunction with too small basis sets (particularly on the metal). Combination B5 shows the same defect when used at the geometries employed in reference 7 , while the larger basis sets do not.

\section{Comparison of the Two Dimethyl Compounds}

In both molecules the bonding between metal and carbon can be described as semipolar with $\sigma$-character. At the SCF-level, neither $p \pi$ contributions nor contributions from $d$ orbitals (for zinc) play a major role.

For C2v symmetry, the two canonical orbitals that bear the major part of MC-bonding belong to the irreducible representations b1(HOMO) and a1 (Fig. 1).

The contribution of the HOMO is responsible for the linear CMC geometry because overlap between the $M-p_{x}$-orbital and the ligand orbitals is favored by this arrangement. The removal of an electron from this MO through excitation to the lowest triplet state $\left(b 1 \rightarrow a 1^{*}\right)$ consequently leads to a bent geometry. Calculations with B3/CEPA 1 or B3/SDCI $+Q$ show this state to have a CMC-angle of ca. $100^{\circ}$ for both molecules, which is consistent with experimental results. ${ }^{24}$

In the magnesium compounds boths MOs have a lower population on the metal than for zinc

Table VII. Mulliken atomic gross charges of the dimethyl compounds.

\begin{tabular}{cccccccc}
\hline & \multicolumn{2}{c}{ Dimethylzinc } & & & \multicolumn{3}{c}{ Dimethylmagnesium } \\
\hline & Zn & C & H & & Mg & C & H \\
\hline B1 & $\mathbf{0 . 3 0 8}$ & -0.491 & 0.112 & & 1.087 & -0.871 & 0.109 \\
B2 & 0.741 & -0.699 & 0.109 & & 1.023 & -0.849 & 0.112 \\
B3 & $\mathbf{0 . 7 1 9}$ & -0.508 & 0.050 & & 0.991 & -0.633 & 0.046 \\
B4 & $\mathbf{0 . 7 3 7}$ & -0.692 & 0.108 & & 1.014 & -0.813 & $\mathbf{0 . 1 0 2}$ \\
B5 & $\mathbf{0 . 6 9 8}$ & -0.718 & 0.127 & & 0.848 & -0.782 & $\mathbf{0 . 1 1 9}$ \\
\hline
\end{tabular}


Table VIII. Mulliken gross populations of the highest occupied MOs in the dimethyl compounds (B4).

\begin{tabular}{ccccccccc}
\hline$M=\mathrm{Zn}$ & $\mathrm{Zn}$ & $\mathrm{C}$ & $\mathrm{H}$ & $M=\mathrm{Mg}$ & $\mathrm{Mg}$ & $\mathrm{C}$ & $\mathrm{H}$ \\
\hline $\mathrm{a} 1$ & 0.640 & 0.621 & 0.020 & & 0.472 & 0.709 & 0.018 \\
$\mathrm{~b} 1$ & 0.336 & 0.775 & 0.019 & & 0.303 & 0.793 & 0.019 \\
\hline
\end{tabular}

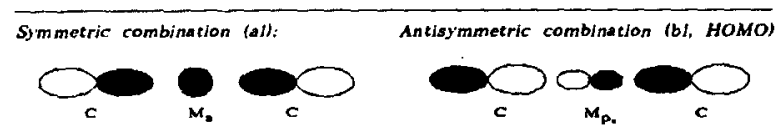

Figure 1. Nodal properties of the highest occupied canonical MOs of the dimethyl compounds.

(Table VIII). Consequently the force constant for CMC-bending is considerably smaller in this case (the numerical values in a.u. are: 0.039 (B1), 0.045 (B4) for $\mathrm{Mg}$; 0.077 (B1), 0.063 (B4) for $\mathrm{Zn}$ ).

Moreover the MC force constants (see Tables III and IV) and the binding energies (see Table X) show the $\mathrm{MgC}$-bond to be weaker.

Together these data strongly support the more ionic character of organomagnesium compounds as compared to organozinc compounds.

\section{Monomethyl Radicals}

To study differences arising from the treatment of open shell systems in comparison to the closed shell dimethyl compounds and to get data about the homolytic MC-bond fission, some of the methods used in the preceding section have been applied to the monomethyl radicals of the two metals.

\section{Geometries and Force Constants}

No experimental data on geometries and force constants for these open shell systems are available. Our calculated results are listed in Table IX.

The MC bond lengthening effect of valence correlation becomes significantly larger than for the dimethyl compounds. For methylzinc the mutual compensation of valence and core valence correlation effects leads to a relatively good agreement between the SCF values and the B1+/CEPA 1 calculations. If only valence correlation is included (B3/CEPA 1) the $\mathrm{ZnC}$-distance is about $6 \mathrm{pm}$ larger. Correspondingly the force constant for this calculation becomes much smaller than for B1+/CEPA 1, whereas the SCF values are somewhat larger (by 10 to 20\%).

Use of the polarization potential improves the $\mathrm{ZnC}$ distance as compared to B3/CEPA 1, but the value is still larger than for $B 1+/ C E P A 1$.

For methylmagnesium the SCF calculations give too small $\mathrm{MgC}$ distances (about 2-3 pm) and force constants about 10 to $20 \%$ too large, again. For both radicals, the SCF calculations slightly underestimate the $\mathrm{CH}$-distances and slightly overestimate the $\mathrm{MCH}$-angles ( $1 \mathrm{pm}$ and $1^{\circ}$ respectively).

\section{MC-Bonding Energies}

To get a measure of the strength of $M C$ bonds in the dimethyl and monomethyl compounds, the following homolytic bond fission reactions were examined:

$$
\begin{gathered}
M\left(\mathrm{CH}_{3}\right)_{2} \rightarrow M-\mathrm{CH}_{3}+\mathrm{CH}_{3} \\
M \mathrm{CH}_{3} \rightarrow M+\mathrm{CH}_{3}
\end{gathered}
$$

For the $\mathrm{CH}_{3}$ radical the calculated $\mathrm{CH}$ distances (109.3 (B1/CEPA 1), 108.5 (B3/CEPA 1), 107.5 (B3) $\mathrm{pm}, D 3 h$ symmetry) were used. The calculated binding energies have not been corrected for zero point vibration.

\begin{tabular}{|c|c|c|c|c|}
\hline Methylzinc & $R-\mathrm{ZnC}[\mathrm{pm}]$ & $<\mathrm{ZnCH}$ & $R-\mathrm{CH}[\mathrm{pm}]$ & $\mathbf{k}(\mathrm{ZnC})$ [a.u.] \\
\hline $\begin{array}{l}\mathrm{B} 1+ \\
\mathrm{B} 3 \\
\mathrm{~B} 1+/ \mathrm{CEPA} 1 \\
\mathrm{~B} 3 / \mathrm{CEPA} 1 \\
\mathrm{~B} 3 / \mathrm{V}_{\mathrm{P} 01} / \mathrm{SDCl}+\mathrm{Q}\end{array}$ & $\begin{array}{l}201.6 \\
202.1 \\
201.0 \\
207.2 \\
203.4\end{array}$ & $\begin{array}{l}110.5 \\
110.8 \\
109.5 \\
109.5 \\
108.8\end{array}$ & $\begin{array}{l}109.5 \\
109.0 \\
110.4 \\
109.7 \\
109.5\end{array}$ & $\begin{array}{l}0.118 \\
0.104 \\
0.096 \\
0.069\end{array}$ \\
\hline Methylmagnesium & $\mathrm{R}-\mathrm{MgC}[\mathrm{pm}]$ & $<\mathrm{MgCH}$ & $R-\mathrm{CH}[\mathrm{pm}]$ & $\mathbf{k}(\mathrm{MgC})$ [a.u.] \\
\hline $\begin{array}{l}\text { B1 } \\
\text { B3 } \\
\text { B1/CEPA } 1 \\
\text { B3/CEPA } 1\end{array}$ & $\begin{array}{l}212.7 \\
211.7 \\
214.5 \\
214.4\end{array}$ & $\begin{array}{l}112.1 \\
112.6 \\
111.3 \\
111.4\end{array}$ & $\begin{array}{l}109.9 \\
109.5 \\
110.7 \\
110.0\end{array}$ & $\begin{array}{l}0.089 \\
0.095 \\
0.077 \\
0.076\end{array}$ \\
\hline
\end{tabular}

Table IX. Geometries and MC force constants of the monomethyl radicals. 
Table X. MC bond dissociation energies $[\mathrm{kJ} / \mathrm{Mol}]$.

\begin{tabular}{|c|c|c|c|c|c|}
\hline$M=\mathbf{Z n}$ & $\mathrm{B} 1+/ \mathrm{CEPA} 1$ & B3/CEPA 1 & $\mathrm{~B} 3 / \mathrm{V}_{\mathrm{Pol}} / \mathrm{SDCI}+\mathrm{Q}$ & B3 & exp." \\
\hline $\begin{array}{l}\mathrm{CH}_{3} \mathrm{Zn}-\mathrm{CH}_{3} \\
\mathrm{Zn}-\mathrm{CH}_{3}\end{array}$ & $\begin{array}{r}-291.7 \\
-47.6\end{array}$ & $\begin{array}{r}-248.7 \\
-23.4\end{array}$ & $\begin{array}{r}-249.8 \\
-25.5\end{array}$ & $\begin{array}{r}-187.8 \\
-1.7\end{array}$ & $\begin{array}{r}-289.6 \\
-81.0\end{array}$ \\
\hline$M=\mathbf{M g}$ & $\mathrm{B} 1+/ \mathrm{CEPA} 1$ & B1/CEPA 1 & B3/CEPA 1 & B3 & \\
\hline $\begin{array}{l}\mathrm{CH}_{3} \mathrm{Mg}-\mathrm{CH}_{3} \\
\mathrm{Mg}-\mathrm{CH}_{3}\end{array}$ & $\begin{array}{r}-248.6 \\
-77.7\end{array}$ & $\begin{array}{r}-233.7 \\
-64.7\end{array}$ & $\begin{array}{r}-229.1 \\
-57.2\end{array}$ & $\begin{array}{r}-162.3 \\
-49.2\end{array}$ & \\
\hline
\end{tabular}

The experimental values of Georgiadis et al. ${ }^{25}$ have error margins of $+/-13.4 \mathrm{~kJ} / \mathrm{Mol}$.

Table X clearly shows that the energy of homolytic $\mathrm{Zn}-\mathrm{C}$ bond fission can only be reliably reproduced by calculations that consider a large part of electron correlation including core valence correlation. For the weak $\mathrm{ZnC}$ bond in methylzinc even $B 1+/$ CEPA 1 gives poor values.

For the magnesium compounds no experimental data are available. As for the other properties of the $\mathrm{Mg}$ compounds valence correlation plays a dominant role.

The result of a seemingly higher dissociation energy of the methylmagnesium radical may well be an artifact of the incomplete treatment of correlation for the zinc compounds (even for $\mathrm{Bl}+1$ CEPA 1). Still these values together with the bond lengths and MC-force constants of the radicals indicate the strengths of the $\mathrm{ZnC}$ - and $\mathrm{MgC}$ bond to be much smaller and more similar for these species than for the dimethyl compounds.

\section{CONCLUSIONS}

The present calculations allow a comparison of the simplest organometallic compounds of zinc and magnesium. Dimethylmagnesium in its monomeric form has been shown to be more ionic than its zinc analogue. The longer $M C$ bond for $M=\mathbf{M g}$ is in good agreement with the larger covalent radius tabulated for magnesium. ${ }^{26}$ But as expected the $\mathrm{MgC}$ distance is still much smaller than the one taken from the solid state structure. ${ }^{3}$ The smaller CMC-bending force constant for $M=\mathrm{Mg}$ as compared to $M=\mathrm{Zn}$ also is consistent with the higher tendency of organomagnesium compounds to polymerize and achieve higher coordination numbers. For the monomethyl radicals the differentiation between the two metals from the present data is less clearcut.

On the SCF level all the pseudopotential/basis set combinations considered give comparable geometries, $M C$ force constants and ionization energies. The atomization energies of the dimethyl compounds show a significant BSSE with the smallest basis sets considered (B5 which is basically a $\mathrm{DZ}$ valence basis set with a small number of primitives for all atoms). Generally the use of this and comparable basis sets is not recommended. The combinations B1 to B3 show similar flexibility, so B3 can be expected to give good results in SCF-calculations on medium-size systems with significant savings in the amount of computer time compared to B1. For large systems B4 seems to be a reasonable compromise.

In addition to the usual bond lengthening effects of valence correlation in main group compounds, for the zinc containing compounds the high polarizability of the $3 d$ shell leads to a valence shell contracting effect of core-valence correlation. For dimethylzinc, therefore, the SCF-values overestimate the $\mathrm{ZnC}$-distance while for methylzinc the even higher core valence- and valence-correlation effects for the $\mathrm{ZnC}$-distance compensate each other to the extent of giving similar $\mathrm{ZnC}$-values in SCF-calculations and calculations considering both correlation components.

A polarization potential in conjunction with the $\operatorname{Ar}\left[3 d^{10}\right]$-core pseudopotential on zinc and valence SDCI+Q-calculations can account for parts of the $\mathrm{ZnC}$ bond shortening effect of core polarization. The results for dimethylzinc are more encouraging than for the methylzinc radical. Only small parts of the influence of core valence correlation on the energies of ionization, atomization and bonding can be recovered, however, by this means.

This study shows that the $a b$ initio calculation of many properties of still larger organozinc and -magnesium compounds with good accuracy seems to be within reach by means of the pseudopotential method.

\section{APPENDIX}

All pseudopotential- and basis set parameters used in this article, that have not been published previously, are listed below. 
Table XI. Parameters for the zinc 2-valence-electron pseudopotential. ${ }^{10}$

\begin{tabular}{ccccc}
\hline$l$ & Exponent & Coefficient & Exponent & Coefficient \\
\hline 0 & 1.4988024 & 18.31672 & 0.7490051 & -3.405011 \\
1 & 1.5327698 & 11.464304 & 0.7870907 & -1.327391 \\
2 & 0.7502758 & 1.583946 & 0.3747915 & 0.3333476 \\
3 & 0.4666989 & -0.398428 & & \\
\hline
\end{tabular}

Table XII. Basis set parameters.

\begin{tabular}{ccrrr}
\hline Element and & \multicolumn{2}{c}{$s$-Functions } & \multicolumn{2}{c}{$p$-Functions } \\
number of primitives & Exponents & Coefficients & Exponents & Coefficients \\
\hline $\mathrm{Zn}$ & 1.842809 & 0.122136 & 0.136715 & 0.534181 \\
$4 s 2 p$ & 1.065847 & -0.360813 & 0.042169 & 0.562075 \\
& 0.165116 & 0.531870 & & \\
$\mathrm{Zn}$ & 0.056048 & 0.618853 & & \\
$3 s 1 p$ & 0.656653 & -0.356621 & 0.085417 & \\
& 0.224679 & 0.522109 & & \\
$\mathrm{Mg}$ & 0.062077 & 0.740140 & & \\
$4 s 2 p$ & 2.425719 & 0.026760 & 0.537735 \\
& 0.822625 & -0.223880 & 0.038620 & \\
$\mathrm{Mg}$ & 0.107749 & 0.620464 & & \\
$3 s 1 p$ & 0.039485 & 0.498607 & & \\
& 1.616690 & 0.141138 & 0.076427 & \\
$\mathrm{C}$ & 1.110157 & -0.302593 & & \\
$4 s 4 p$ & 0.070333 & 1.050649 & & \\
& 2.581190 & -0.289364 & 8.257547 & 0.042311 \\
$\mathrm{C}$ & 1.596882 & 0.209015 & 1.960285 & 0.211185 \\
$3 s 3 p$ & 0.408595 & 0.601018 & 0.551454 & 0.500500 \\
& 0.138945 & 0.451515 & 0.155007 & 0.469981 \\
& 3.083822 & -0.170171 & 4.363067 & 0.108191 \\
& 0.558944 & 0.537878 & 0.906016 & 0.456769 \\
\hline
\end{tabular}

This work was supported by the "Schwerpunktprogramm Pseudopotentiale des Landes BadenWürttemberg." We are grateful to M. Dolg for providing his unpublished zinc pseudopotential and for helpful discussions. Thanks are also due to Prof. H.J. Werner (Bielefeld) for providing his version of the program MOLPRO.

\section{References}

1. W. A. Herrmann, Kontakte (Darmstadt), 1, 3 (1988).

2. A. Almenningen, T. U. Helgaker, A. Haaland, and S. Samdal, Acta Chem. Scand. Ser. A, A36, 159 (1982).

3. a. E. Weiss, J. Organomet. Chem., 2, 314 (1964). b. E. Weiss, J. Organomet. Chem., 4, 101 (1965).

4. M. Kaupp, H. Stoll, W. Kaim, G. v. Koten, and $H$. Preuss, to be published.

5. a. D. Jayatilaka, R. D. Amos, N. Koga, Chem. Phys. Lett., 163, 151 (1989). b. Z. Barandiaran, L. Sejo, S. Huzinaga, and M. Klobukowski, Int. J. Quant. Chem., 29, 1047 (1986).

6. G. E. Quelch and I. H. Hillier, J. Chem. Soc. Faraday Tr. 2, 83, 1637 (1987).

7. M. A. Ratner, J.W. Moskowitz, and S. Topiol, J. Am. Chem. Soc., 100, 2392 (1978),

8. M. Dolg, U. Wedig, H. Stoll, and H. Preuss, J. Chem. Phys., 86, 866 (1987).
9. U. Wedig, M. Dolg, H. Stoll, and H. Preuss, in The Challenge of Transition Metals and Coordination Chemistry, A. Veillard (ed.), Reidel 1986, p. 79.

10. M. Dolg, unpublished results.

11. a. W. Müller, J. Flesch and W. Meyer, J. Chem. Phys., 80, 3297 (1984). b. G. Igel-Mann, Thesis, Institut für Theoretische Chemie, Universität Stuttgart, 1987.

12. P. Fuentealba, L.v. Szentpäly, H. Preuss, and H. Stoll, J. Phys. B, 73, 1287 (1985).

13. G. Igel-Mann, H. Stoll, and H. Preuss, Mol. Phys., 65, 1321 (1988).

14. A.D. McLean and G.S. Chandler: J. Chem. Phys., 72,5639 (1980).

15. T. H. Dunning and H. Hay, in Methods of Electronic Structure Theory (Modern Theoretical Chemistry, Vol. 3), H. F. Schaefer III (ed.), Plenum Press, New York, 1977.

16. J.H. Wood and A. M. Boring, Phys. Rev. B, 18, 2701 (1978).

17. S. R. Langhoff and E. R. Davidson, Int. J. Quant. Chem., 8, 61 (1974).

18. a. W. Meyer, J. Chem. Phys., 58, 1017 (1973). b. W. Meyer, J. Chem. Phys., 64, 2901 (1976).

19. L. McMurchie, S. T. Elbert, S. Langhoff, and E. R. Davidson, Program MELD, University of Washington, Seattle 1982.

20. H.J. Werner, University of Bielefeld, and W. Meyer, University of Kaiserslautern, Program MOLPRO, 
1987 (see, e.g., H.J. Werner, Adv. Chem. Phys., 69, 1 (1987).

21. I. S. Butler and M. L. Newbury, Spectrochim. Acta, A33, 699 (1977)

22. J.S. Tse, G. M. Bancroft, and D.K. Creber, J. Chem. Phys., 74, 2097 (1981).

23. S. F. Boys and F. Bernardi, Mol. Phys., 19, 553 (1970).
24. C. F. Yu, F. Youngs, K. Tsukiyama, R. Bersohn, and J. Preses, J. Chem. Phys., 85, 1382 (1986).

25. R. Georgiadis and P. B. Armentrout, J. Am. Chem. Soc., 108, 2119 (1986).

26. L. Sutton (ed.), Tables of Interatomic Distances and Configurations in Molecules and Ions, Spec. Publ. No. 11, 18, The Chem. Soc., London, 1958, 1965. 